ECOLOGICA, Vol. 28, No 103 (2021), 481-486

https://doi.org/10.18485/ecologica.2021.28.103.20

Originalni naučni rad

UDC: 628.477

669.053.4

\title{
Laboratorijska istraživanja luženja Cu, Zn i In iz otpadnog taloga jarozita
}

\section{Laboratory research on acid leaching of $\mathrm{Cu}, \mathrm{Zn}$ and $\mathrm{In}$ from jarosite waste}

Dragana Božići ${ }^{*}$, Vesna Conić2 , Suzana Dragulović ${ }^{3}$ Ljiljana Avramović ${ }^{4}$, Radojka Jonović5, Mile Bugarin ${ }^{6}$

1,2,3,4,5,6 Institut za rudarstvo i metalurgiju Bor, Zeleni bulevar 35, 19210 Bor, Srbija /

Mining and Metallurgy Institute Bor, Zeleni bulevar 35, 19210 Bor, Serbia

*Autor za prepisku / Corresponding author

Rad primljen / Received: 09.12.2020, Rad prihvaćen / Accepted: 07.08.2021.

Sažetak: $U$ radu su prikazani rezultati tretmana tehnogene sirovine, otpadnog taloga jarozita postupkom luženja radi valorizacije ekonomski vrednih metala $\mathrm{Cu}, \mathrm{Zn}$ i In i minimiziranja negativnog uticaja lužnog ostatka na zivotnu sredinu. Najpre je uzorak homogenizovan, a zatim je urađena granulometrijska, XRD i hemijska analiza uzorka jarozita. Primenjeni agensi za proces luženja bili su $\mathrm{HCl}, \mathrm{HNO}_{3}, \mathrm{NaCl}$ i $\mathrm{H}_{2} \mathrm{SO}_{4}$. Istraživanja su pokazala da je najprihvatljiviji postupak tretmana jarozita luženje jarozita sumpornom kiselinom, pri čemu su dobijena najbolja izluženja Cu, Zn i In i to 93,76\%, 91,64 i 97,59\% respektivno.

Ključne reči: hidrometalurgija, luženje, jarozit, cink, bakar, indijum, talog, otpad.

\begin{abstract}
The paper presents the results of treatment of technogenic raw materials by the leaching process in order to valorize economically valuable metals $\mathrm{Cu}, \mathrm{Zn}$ and $\mathrm{In}$ and minimize the negative impact of leached residue on the environment. First, the sample was homogenized, and then granulometric, $\mathrm{XRD}$ and chemical analysis of the jarosite sample was done. The leaching agents used in experiments were $\mathrm{HCl}, \mathrm{HNO}_{3}, \mathrm{NaCl}$ and $\mathrm{H}_{2} \mathrm{SO}_{4}$. Investigations have shown that the most acceptable method for the treatment of jarosite is leaching of jarosite using sulfuric acid, where the best leaching of $\mathrm{Cu}, \mathrm{Zn}$ and $\mathrm{In}$ was obtained, namely $93.76 \%, 91.64$ and $97.59 \%$, respectively.
\end{abstract}

Keywords: hydrometallurgy, leaching, jarosite, copper, zinc, indium, residue, waste.

\footnotetext{
${ }^{1}$ orcid.org/0000-0003-1055-8449, e-mail: dragana.bozic@irmbor.co.rs 2orcid.org/0000-0002-4268-3626, e-mail: vesna.conic@irmbor.co.rs ${ }^{3}$ orcid.org/0000-0001-5086-5115, e-mail: suzana.dragulovic@irmbor.co.rs 4orcid.org/0000-0002-3747-1530, e-mail: ljiljana.avramovic@irmbor.co.rs ${ }^{5}$ orcid.org/0000-0002-8115-3134, e-mail: radojka.jonovic@irmbor.co.rs 6orcid.org/0000-0002-6992-5154, e-mail: mile.bugarin@irmbor.co.rs
} 


\section{UVOD / INTRODUCTION}

Eksploatacijom bogatih ruda sve više opada kvalitet ruda koje se dalje eksploatišu pa dolazi do smanjenja cene metala. Jači ekološki propisi i sve veća svest o zdravlju i sigurnosti trenutno su neki od glavnih izazova s kojima se suočava industrija cinka.

Sa eksploatacijom i preradom ruda cinka primenom hidrometalurskog postupka prerade sirovine dolazilo je do stvaranja i nagomilavanja nusprodukta koji sadrzi skoncentrisane vrednosne metale. Na taj način ovi resursi pretvoreni su u rezerve. Time se istovremeno može postići maksimiranje profita, kao jedan od glavnih ciljeva poslovanja svake kompanije.

Sve veća složenost rudnih ležišta, opadanje kvaliteta ruda i veća globalna potražnja za cinkom rezultirali su povećanom preradom rude širom sveta. Iscrpljivanje visokokvalitetnih ruda, povećana potražnja za metalima i poteškoće u odvajanju povezane sa niskokvalitetnim ili složenim rudama, rezultirale su novim izazovima u smislu ekonomskog i održivog iskorišćavanja tih ruda.

Koncentrati cinka, pored cinka, u sebi sadrže i čitav niz komercijalno značajnih metala kao što su bakar, olovo, srebro, germanijum, indijum, galijum itd. Ovi metali ne stvaraju sopstvena mineralna ležišta, već se kao pratioci cinka, u hidrometalurškoj proizvodnji cinka, prženjem, luženjem i elektrolitičkom ekstrakcijom, koncentrišu u izlaznim talozima tzv. jarozitima kao nusprodukti (Yong et al.,, 2016, Yayun et al.,, 2018). Preradom nusprodukata mogu se valorizovati mnogi metali što povoljno utiče na ukupnu ekonomiju osnovnog procesa, jer su cene ovih metala relativno visoke (Milićević i dr., 2020, Stanojević i dr., 2014, Stanojević i dr., 1998) .

Jarozit, kao novonastala hemijska struktura, veoma je stabilan i slabo je rastvoran u razblaženoj kiselini (Stanojević i dr., 2006). Prateći metali cinka iz jarozita obično se dobijaju Waelz pirometalurskim postupkom. Pirometalurški procesi prerade sekundarnih sirovina cinka i otpadnih taloga iz hidrometalurgije cinka su veoma efikasni, ali podrazumevaju skupa industrijska postrojenja velikog kapaciteta, da bi mogla biti ekonomična. Pri ovim procesima oslobađaju se štetni gasovi koji mogu da imaju ozbiljan uticaj na zivotnu sredinu (llić i dr., 2019). Neki autori prikazali su da se primenom pirometalurških procesa kao što su Waelz i Ausmelt metode troši ogromna količina uglja da bi se obezbedila snaga potrebna za postizanje visoke radne temperature $\left(1100-1300^{\circ} \mathrm{C}\right)$. Ove metode nisu ekonomski isplative pa se zbog toga jaroziti obično deponuju.

Cilj ovog rada bio je da se primenom hidrometalurškog postupka luženja, pored cinka, valorizuju i neki od pratećih metala kao što su Cu i In. Hid- rometalurškom preradom jarozitnog otpada dodatno bi se povećala količina proizvedenog cinka a ostali metali $\mathrm{Cu}$ i In bi se dodatno valorizovali što podržava integrisani pristup dobijanja metala u hidrometalurgiji cinka.

\section{MATERIJALI I METODE / MATERIALS AND METHODS}

\section{Karakterizacija jarozita}

\section{Granulometrijski sastav uzorka}

Dobijeni originalni uzorak jarozita je osušen i homogenizovan a zatim je urađena granulometrijska analiza koja je prikazana u Tabeli 1.

Tabela 1 - Granulometrijski sastav uzorka jarozita Table 1 - Granulometric composition of jarosite sample

\begin{tabular}{|c|c|c|c|}
\hline $\begin{array}{c}\text { Klasa } \\
\text { krupnoće } \\
d(m m)\end{array}$ & $\begin{array}{c}\text { Maseno } \\
\text { učešće } \\
\mathrm{m} \%\end{array}$ & $\begin{array}{c}\text { Kumulativ- } \\
\text { no učešće } \\
\text { po plusu } \\
\mathrm{R} \%\end{array}$ & $\begin{array}{c}\text { Kumulativ- } \\
\text { no učešće } \\
\text { po minusu } \\
\mathrm{D} \%\end{array}$ \\
\hline$-0,150+0,106$ & 0,50 & 0,50 & 100 \\
\hline$-0,106+0,075$ & 0,25 & 0,75 & 99,50 \\
\hline$-0,075+0,053$ & 0,30 & 1,05 & 99,25 \\
\hline$-0,053+0,038$ & 0,30 & 1,35 & 98,95 \\
\hline$-0,038+0,020$ & 0,15 & 1,50 & 98,65 \\
\hline$-0,020+0,000$ & 98,50 & 100 & 98,50 \\
\hline
\end{tabular}

Granulometrijska analiza je pokazala da je veličina čestica ispod $38 \mu \mathrm{m}$ prisutna u količini od $98,65 \%$. Radi što bolje ekstrakije metala uzorak je samleven na veličinu zrna $98,50 \%-20 \mu m$ i ponovo homogenizovan.

\section{Mineraloška analiza uzorka}

Rendgensko-difrakciona (XRD) analiza, vršena je na instrumentu „Rigaku MiniFlex 600“ sa „D/teX Ultra 250" detektorom visoke brzine i rendgenskom cevi sa bakarnom anodom. Granica detekcije XRD analize je oko $1 \%$. Difraktogram dobijen XRD analizom prikazan je na Slici 1.

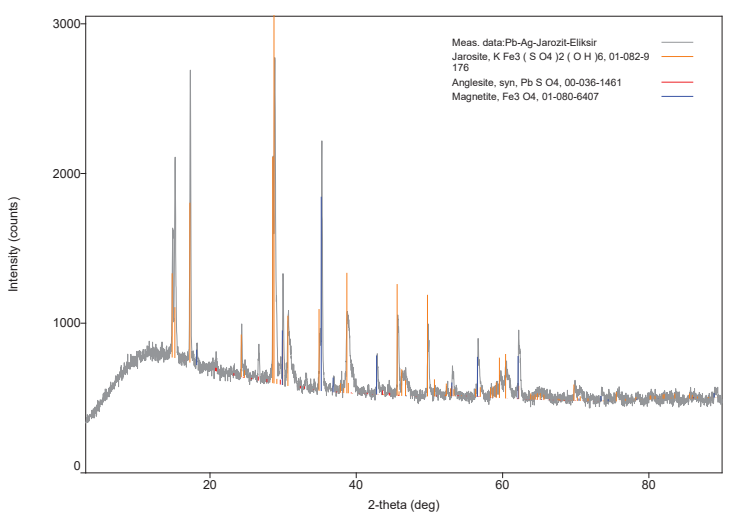

Slika 1 - Difraktogram uzorka jarozita

Figure 1 - Diffractogram of jarosite sample 
XRD analiza jarozita pokazala je da su u uzorku prisutni sledeći minerali: jarosit $\left(\mathrm{KFe}_{3}\left(\mathrm{SO}_{4}\right)_{2}(\mathrm{OH})_{6}\right)$, magnetit $\left(\mathrm{Fe}_{3} \mathrm{O}_{4}\right)$ i anglezit $\left(\mathrm{PbSO}_{4}\right)$. Takođe se može videti da su jarozit i magnetit najzastupljeniji minerali u uzorku, dok je anglezit manje zastupljen.
Hemijska karakterizacija uzorka jarozita

Nakon homogenizacije uzorka jarozita izdvojen je reprezentativni uzorak i urađena je hemijska analiza. Hemijska analiza uzorka prikazana je u Tabeli 2.

Tabela 2 - Hemijska analiza uzorka jarozita / Table 2 - Chemical analysis of jarosite sample

\begin{tabular}{|c|c|c|c|c|c|c|c|c|c|c|c|}
\hline $\begin{array}{c}\mathrm{Cu} \\
(\%)\end{array}$ & $\begin{array}{c}\mathrm{Zn} \\
(\%)\end{array}$ & $\begin{array}{c}\mathrm{Pb} \\
(\%)\end{array}$ & $\begin{array}{c}\mathrm{In} \\
(\mathrm{ppm})\end{array}$ & $\begin{array}{c}\mathrm{Ga} \\
(\mathrm{ppm})\end{array}$ & $\begin{array}{c}\mathrm{Ge} \\
(\mathrm{ppm})\end{array}$ & $\begin{array}{c}\mathrm{Al} \\
(\%)\end{array}$ & $\begin{array}{c}\mathrm{As} \\
(\%)\end{array}$ & $\begin{array}{c}\mathrm{Mn} \\
(\%)\end{array}$ & $\begin{array}{c}\mathrm{Sn} \\
(\%)\end{array}$ & $\begin{array}{c}\mathrm{Sb} \\
(\%)\end{array}$ & $\begin{array}{c}\mathrm{Mg} \\
(\%)\end{array}$ \\
\hline 0,7 & 5,39 & 5,68 & 343,2 & 101,7 & 11.32 & 0,33 & 0,26 & 0,14 & 0,062 & 0,060 & 0,022 \\
\hline
\end{tabular}

\begin{tabular}{|c|c|c|c|c|c|c|c|c|c|c|c|}
\hline $\begin{array}{c}\mathrm{Ti} \\
(\%)\end{array}$ & $\begin{array}{c}\mathrm{Ca} \\
(\%)\end{array}$ & $\begin{array}{c}\mathrm{S} \\
(\%)\end{array}$ & $\begin{array}{c}\mathrm{Fe} \\
(\%)\end{array}$ & $\begin{array}{c}\mathrm{Cr} \\
(\mathrm{ppm})\end{array}$ & $\begin{array}{c}\mathrm{V} \\
(\mathrm{ppm})\end{array}$ & $\begin{array}{c}\mathrm{Ni} \\
(\mathrm{ppm})\end{array}$ & $\begin{array}{c}\mathrm{Mo} \\
(\mathrm{ppm})\end{array}$ & $\begin{array}{c}\mathrm{Rb} \\
(\mathrm{ppm})\end{array}$ & $\begin{array}{c}\mathrm{Nb} \\
(\mathrm{ppm})\end{array}$ & $\begin{array}{c}\mathrm{La} \\
(\mathrm{ppm})\end{array}$ & $\begin{array}{c}\mathrm{Nd} \\
(\mathrm{ppm})\end{array}$ \\
\hline 0,018 & 0,066 & 9.61 & 30,61 & 46,7 & 26,9 & 17,8 & 58,4 & 3,6 & 0,85 & 2,4 & 1,9 \\
\hline
\end{tabular}

\begin{tabular}{|c|c|c|c|}
\hline $\begin{array}{c}\mathrm{Tl} \\
(\mathrm{ppm})\end{array}$ & $\begin{array}{c}\mathrm{Cd} \\
(\mathrm{ppm})\end{array}$ & $\begin{array}{c}\mathrm{Ag} \\
(\mathrm{g} / \mathrm{t})\end{array}$ & $\begin{array}{c}\mathrm{Au} \\
(\mathrm{g} / \mathrm{t})\end{array}$ \\
\hline 50,7 & 368 & 343 & 1,3 \\
\hline
\end{tabular}

\section{REZULTATI I DISKUSIJA / RESULTS AND DISCUSSION}

\section{Eksperimenti luženja jarozita}

Luženja jarozita vršena su u cilju ekstrakcije metala: Cu, Zn i In. Luženja su vršena u staklenim čašama na magnetnoj mešalici sa mešanjem i grejanjem uz uvođenje vazduha za neophodne procese, Slika 2.

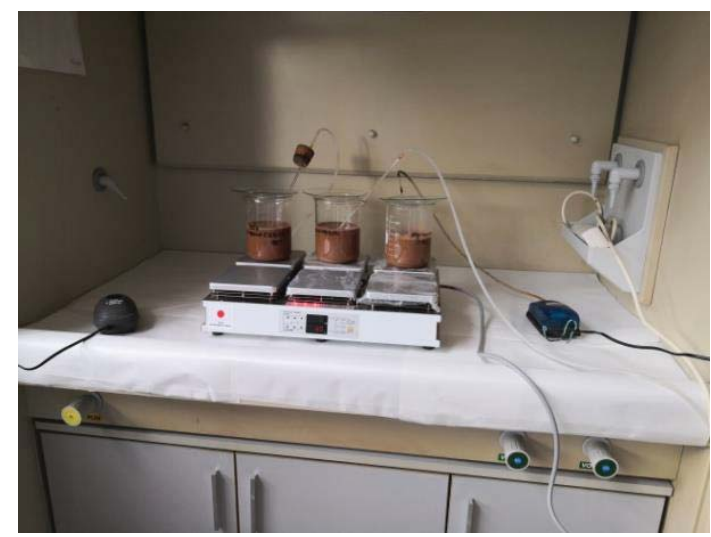

Slika 2 - Luženje jarozita na magnetnoj mešalici Figure 2 - Leaching of jarosite on a magnetic stirrer

Tokom laboratorijskih istraživanja primenjeno je četiri vrste luženja:

- Luženje hlorovodoničnom kiselinom,

- Luženje azotnom kiselinom,

- Luženje u rastvoru natrijum hlorida,

- Luženje sumpornom kiselinom.

Nakon luženja svaki uzorak je profiltriran i ispran, a zapremine rastvora sa ispirnim vodama su izmerene i date na hemijsku analizu.

\section{Luženje hlorovodoničnom kiselinom uz uvođenje vazduha}

Luženje u hlorovodoničnoj kiselini vršeno je menjanjem parametara: koncentracije kiseline, temperature i vremena luženja. Rezultati izluženja metala prikazani su u Tabeli 3.

Iz tabele se može videti da se luženjem sa $20 \%$ $\mathrm{HCl}$ na temperaturi $60^{\circ} \mathrm{C}$, vremenu luženja $1 \mathrm{~h}$, pri odnosu faza Č:T=1:4 može postići preko $70 \%$ izluženje Cu, preko $90 \%$ izluženje Zn i preko $90 \%$ izluženje In.

\section{Luženje azotnom kiselinom}

Luženje u azotnoj kiselini vršeno je pri sledećim uslovima:

- koncentraciji kiseline $20 \% \mathrm{HNO}_{3}$,

- temperaturi $60^{\circ} \mathrm{C}$,

- vremenu $6 \mathrm{~h} \mathrm{i}$

- $\quad$ pri odnosu faza Č:T=1:5.

Stepeni izluženja metala prikazani su u Tabeli 4.

Luženje $u$ azotnoj kiselini pokazalo je relativno dobro izluženje In ali i relativno niska izluženja $\mathrm{Cu}$ i Zn.

\section{Luženje u rastvoru natrijum hlorida}

Hloridno luženje jarozita u rastvoru natrijum hlorida izvršeno je pri sledećim uslovima:

- koncentacija $\mathrm{NaCl}: 250 \mathrm{~g} / \mathrm{L}, 300 \mathrm{~g} / \mathrm{L}, 350 \mathrm{~g} / \mathrm{L}$,

- temperatura: $80^{\circ} \mathrm{C}$,

- vreme luženja: $20 \mathrm{~min}$,

- odnos faza Č:T=1:20,

Izbor parametara luženja izvršen je na osnovu rezultata istraživanja olova iz olovo-sulfata. U Tabeli 5 , prikazani su procenti izluženja metala. 
Povećanje koncentracije $\mathrm{NaCl}$ u rastvoru nije uticalo na povećanje stepena izluženja metala.

Nakon hloridnog luženja korišćenjem parametara $\left(250 \mathrm{~g} / \mathrm{L} \mathrm{NaCl}, 80^{\circ} \mathrm{C}\right.$, vreme luženja $20 \mathrm{~min}$, Č:T=1:20) dobijeni čvrsti ostatak podvrgnut je luženju u sumpornoj kiselini.

Čvrsti ostatak nakon hloridnog luženja je ispran, osušen i lužen u sumpornoj kiselini pri sledećim uslovima (ovi uslovi luženja odabrani su na osnovu prethodnih iskustava u luženju sličnih sirovina):

- koncentacija kiseline: $10 \% \mathrm{H}_{2} \mathrm{SO}_{4}$,

- temperatura: $60^{\circ} \mathrm{C}$,

- vreme luženja: $6 \mathrm{~h}$,

- odnos faza Č:T=1:4.
U Tabeli 6, prikazana su izluženja metala nakon luženja u sumpornoj kiselini, a u Tabeli 7 , kumulativno izluženje metala nakon hloridnog i sulfatnog luženja.

Sulfatno luženje pokazalo je značajniji procenat izluženja metala u odnosu na hloridno luženje, međutim kumulativno izluženje nije pokazalo dovoljno dobar rezultat koji bi bio prihvaćen.

\section{Luženje sumpornom kiselinom uz uvođenje vazduha}

Luženje sumpornom kiselinom urađeno je korišćenjem različitih koncentracija kiseline od $2 \%$ $15 \%$, pri različitim uslovima: temperature, vremena luženja i odnosa faza. Rezultati izluženja metala prikazani su u Tabeli 8.

Tabela 3 - Stepen izluženja metala luženjem u HCl

Table 3 - Recovery of metals by $\mathrm{HCl}$ leaching

\begin{tabular}{|c|c|c|c|c|c|c|}
\hline \multirow{2}{*}{ Konc. kis. } & \multirow{2}{*}{ Temp. } & \multirow{2}{*}{$\begin{array}{l}\text { Vreme } \\
\text { luženja }\end{array}$} & \multirow{2}{*}{$\begin{array}{c}\text { Odnos } \\
\text { faza }\end{array}$} & \multicolumn{3}{|c|}{ Stepen izluženja (\%) } \\
\hline & & & & $\mathrm{Cu}$ & $\mathrm{Zn}$ & $\ln$ \\
\hline $10 \%$ & sobna & $1 \mathrm{~h}$ & Č:T=1:4 & 19,70 & 14,83 & 17,02 \\
\hline $10 \%$ & $60^{\circ} \mathrm{C}$ & $1 \mathrm{~h}$ & Č:T=1:4 & 43,99 & 35,06 & 64,03 \\
\hline $10 \%$ & $80^{\circ} \mathrm{C}$ & $1 \mathrm{~h}$ & Č:T=1:4 & 56,00 & 52,86 & 95,06 \\
\hline $20 \%$ & $60^{\circ} \mathrm{C}$ & $1 \mathrm{~h}$ & Č:T=1:4 & 70,25 & 92,12 & 98,00 \\
\hline $20 \%$ & $60^{\circ} \mathrm{C}$ & $2 \mathrm{~h}$ & Č:T=1:4 & 68,83 & 57,60 & 99,12 \\
\hline $20 \%$ & $60^{\circ} \mathrm{C}$ & $4 \mathrm{~h}$ & Č:T=1:4 & 78,34 & 70,88 & 99,01 \\
\hline $20 \%$ & $60^{\circ} \mathrm{C}$ & $6 \mathrm{~h}$ & Č:T=1:4 & 87,24 & 95,20 & 98,50 \\
\hline
\end{tabular}

Tabela 4 - Stepen izluženja metala luženjem u azotnoj kiselini

Table 4 - Recovery of metals by nitric acid leaching

\begin{tabular}{|c|c|c|c|c|c|c|}
\hline \multirow{2}{*}{ Konc. kis. } & \multirow{2}{*}{ Temp. } & \multirow{2}{*}{$\begin{array}{c}\text { Vreme } \\
\text { luženja }\end{array}$} & \multirow{2}{*}{$\begin{array}{c}\text { Odnos } \\
\text { faza }\end{array}$} & \multicolumn{3}{|c|}{ Stepen izluženja (\%) } \\
\cline { 5 - 7 } & & $6 \mathrm{Cu}$ & $\mathrm{Zn}$ & $\mathrm{In}$ \\
\hline $10 \%$ & $60^{\circ} \mathrm{C}$ & $6 \mathrm{~h}$ & $\mathrm{~S}: \mathrm{L}=1: 5$ & 40.25 & 39.50 & 63.33 \\
\hline $15 \%$ & $60^{\circ} \mathrm{C}$ & $6 \mathrm{~h}$ & $\mathrm{~S}: \mathrm{L}=1: 5$ & 47.39 & 44.22 & 68.10 \\
\hline $20 \%$ & $60^{\circ} \mathrm{C}$ & $6 \mathrm{~h}$ & $\mathrm{~S}: \mathrm{L}=1: 5$ & 50.79 & 47.41 & 71.20 \\
\hline
\end{tabular}

Tabela 5 - Stepen izluženja metala luženjem u rastvoru $\mathrm{NaCl}$

Table 5 - Recovery of metals by $\mathrm{NaCl}$ leaching

\begin{tabular}{|c|c|c|c|c|c|c|}
\hline \multirow{2}{*}{ Konc. soli } & \multirow{2}{*}{ Temp. } & \multirow{2}{*}{$\begin{array}{c}\text { Vreme } \\
\text { luženja }\end{array}$} & \multirow{2}{*}{$\begin{array}{c}\text { Odnos } \\
\text { faza }\end{array}$} & \multicolumn{3}{|c|}{ Stepen izluženja (\%) } \\
\cline { 5 - 7 } & & & & $\mathrm{Cu}$ & $\mathrm{Zn}$ & $\mathrm{In}$ \\
\hline $250 \mathrm{~g} / \mathrm{L}$ & $80^{\circ} \mathrm{C}$ & $20 \mathrm{~min}$ & Č: $\mathrm{T}=1: 20$ & 1,43 & 7,21 & 1,20 \\
\hline $300 \mathrm{~g} / \mathrm{L}$ & $80^{\circ} \mathrm{C}$ & $20 \mathrm{~min}$ & Č: $\mathrm{T}=1: 20$ & 1,48 & 5,57 & 0,90 \\
\hline $350 \mathrm{~g} / \mathrm{L}$ & $80^{\circ} \mathrm{C}$ & $20 \mathrm{~min}$ & Č: $\mathrm{T}=1: 20$ & 1,16 & 7,04 & 0,35 \\
\hline
\end{tabular}

Tabela 6 - Stepen izluženja metala nakon luženja u rastvoru $\mathrm{H}_{2} \mathrm{SO}_{4}$

Table 6 - Recovery of metals by $\mathrm{H}_{2} \mathrm{SO}_{4}$ leaching

\begin{tabular}{|c|c|c|c|c|c|c|}
\hline \multirow{2}{*}{ Konc. kis. } & \multirow{2}{*}{ Temp. } & \multirow{2}{*}{$\begin{array}{c}\text { Vreme } \\
\text { luženja }\end{array}$} & \multirow{2}{*}{$\begin{array}{c}\text { Odnos } \\
\text { faza }\end{array}$} & \multicolumn{3}{|c|}{ Stepen izluženja (\%) } \\
\cline { 5 - 7 } & & $6 \mathrm{Cu}$ & $\mathrm{C}: \mathrm{T}=1: 4$ & 46,57 & $\mathrm{Zn}$ & $\mathrm{In}$ \\
\hline $10 \%$ & $60^{\circ} \mathrm{C}$ & 63,48 & 34,70 \\
\hline
\end{tabular}


Tabela 7 - Kumulativno izluženje nakon hloridnog i sulfatnog luženja

Table 7 - Cumulative leaching after chloride and sulphate leaching

\begin{tabular}{|c|c|c|c|c|c|c|}
\hline \multicolumn{4}{|c|}{ Uslovi hloridnog i sulfatnog luženja } & $\mathrm{Cu}(\%)$ & Zn (\%) & $\ln (\%)$ \\
\hline $250 \mathrm{~g} / \mathrm{L}$ & $80^{\circ} \mathrm{C}$ & $20 \mathrm{~min}$ & Č:T=1:20 & 1,43 & 7,21 & 1,20 \\
\hline $10 \%$ & $60^{\circ} \mathrm{C}$ & $6 \mathrm{~h}$ & Č:T=1:4 & 46,57 & 43,48 & 34,72 \\
\hline \multicolumn{4}{|c|}{ Kumulativno izluženje } & 48,00 & 50,69 & 35,92 \\
\hline
\end{tabular}

Tabela 8 - Stepen izluženja metala u rastvoru sumporne kiseline

Table 8 - Recovery of metals by $\mathrm{H}_{2} \mathrm{SO}_{4}$ leaching

\begin{tabular}{|c|c|c|c|c|c|c|c|}
\hline \multirow{2}{*}{$\begin{array}{c}\text { Redni broj } \\
\text { eksperimenta }\end{array}$} & \multirow{2}{*}{$\begin{array}{l}\text { Konc. } \\
\text { kis. }\end{array}$} & \multirow{2}{*}{ Temp. } & \multirow{2}{*}{$\begin{array}{l}\text { Vreme } \\
\text { luženja }\end{array}$} & \multirow{2}{*}{$\begin{array}{l}\text { Odnos } \\
\text { faza }\end{array}$} & \multicolumn{3}{|c|}{ Stepen izluženja (\%) } \\
\hline & & & & & $\mathrm{Cu}$ & $\mathrm{Zn}$ & In \\
\hline 1. & $2 \%$ & $60^{\circ} \mathrm{C}$ & $6 \mathrm{~h}$ & Č:T=1:4 & 7,87 & 13,22 & 6,50 \\
\hline 2. & $5 \%$ & $60^{\circ} \mathrm{C}$ & $6 \mathrm{~h}$ & Č:T=1:4 & 23,25 & 31,20 & 19,70 \\
\hline 3. & $10 \%$ & $60^{\circ} \mathrm{C}$ & $6 \mathrm{~h}$ & Č:T=1:4 & 46,98 & 47,49 & 42,70 \\
\hline 4. & $15 \%$ & $60^{\circ} \mathrm{C}$ & $6 \mathrm{~h}$ & Č:T=1:4 & 44,87 & 67,93 & 70,04 \\
\hline 5. & $2 \%$ & $90^{\circ} \mathrm{C}$ & $6 \mathrm{~h}$ & Č:T=1:4 & 10,15 & 17,81 & 5,13 \\
\hline 6. & $5 \%$ & $90^{\circ} \mathrm{C}$ & $6 \mathrm{~h}$ & Č:T=1:4 & 29,47 & 51,28 & 18,95 \\
\hline 7. & $10 \%$ & $90^{\circ} \mathrm{C}$ & $6 \mathrm{~h}$ & Č:T=1:4 & 54,15 & 82,97 & 37,10 \\
\hline 8. & $15 \%$ & $90^{\circ} \mathrm{C}$ & $6 \mathrm{~h}$ & Č:T=1:4 & 55,31 & 76,19 & 52,75 \\
\hline 9. & $2 \%$ & $90^{\circ} \mathrm{C}$ & $1 \mathrm{~h}$ & Č:T=1:4 & 12,10 & 22,02 & 6,63 \\
\hline 10. & $5 \%$ & $90^{\circ} \mathrm{C}$ & $1 \mathrm{~h}$ & Č:T=1:4 & 23,46 & 33,87 & 14,91 \\
\hline 11. & $10 \%$ & $90^{\circ} \mathrm{C}$ & $1 \mathrm{~h}$ & Č:T=1:4 & 44,09 & 30,19 & 37,80 \\
\hline 12. & $10 \%$ & $90^{\circ} \mathrm{C}$ & $6 \mathrm{~h}$ & Č:T=1:5 & 53,17 & 61,46 & 42,96 \\
\hline 13. & $10 \%$ & $90^{\circ} \mathrm{C}$ & $6 \mathrm{~h}$ & Č:T=1:10 & 75,80 & 84,96 & 77,50 \\
\hline 14. & $10 \%$ & $90^{\circ} \mathrm{C}$ & $6 \mathrm{~h}$ & Č:T=1:15 & 87,85 & 72,08 & 96,80 \\
\hline 15. & $15 \%$ & $60^{\circ} \mathrm{C}$ & $1 \mathrm{~h}$ & Č:T=1:4 & 54,54 & 51,18 & 59,90 \\
\hline 16. & $15 \%$ & $90^{\circ} \mathrm{C}$ & $1 \mathrm{~h}$ & Č:T=1:4 & 54,85 & 63,96 & 56,12 \\
\hline 17. & $15 \%$ & $90^{\circ} \mathrm{C}$ & $6 \mathrm{~h}$ & Č:T=1:5 & 68,68 & 73,02 & 68,50 \\
\hline 18. & $15 \%$ & $90^{\circ} \mathrm{C}$ & $6 \mathrm{~h}$ & Č:T=1:10 & 93,76 & 91,64 & 97,59 \\
\hline 19. & $15 \%$ & $90^{\circ} \mathrm{C}$ & $6 \mathrm{~h}$ & Č:T=1:15 & 93,48 & 80,04 & 98,74 \\
\hline 20. & $20 \%$ & $90^{\circ} \mathrm{C}$ & $6 \mathrm{~h}$ & Č:T=1:5 & 93,34 & 90,88 & 99,07 \\
\hline 21. & $30 \%$ & $90^{\circ} \mathrm{C}$ & $6 \mathrm{~h}$ & Č:T=1:5 & 93,39 & 88,36 & 98,80 \\
\hline
\end{tabular}

U tabeli 8, su prikazani različiti uslovi luženja, pri kojima su dobijena različita izluženja metala. Iz tabele se može videti da pri luženju jarozita korišćenjem $15 \% \mathrm{H}_{2} \mathrm{SO}_{4}$, pri temperaturi od $90^{\circ} \mathrm{C}$, vremenu luženja $6 \mathrm{~h}$, pri odnosu faza Č: $T=1: 10$, uz uvođenje vazduha, izluženja $\mathrm{Cu}$ i $\mathrm{Zn}$ iznose preko $90 \%$ pojedinačno, a izluženje In $97,59 \%$. Pri ovim uslovima izvršen je jedan eksperiment bez uvođenja vazduha. Rezultati su pokazali da je procenat izluženja metala bio isti, što znači da je proces moguć bez uvođenja vazduha. Istraživanja nekih autora su pokazala da se tretiranjem sličnog materijala pri gotovo istim uslovima (eksperiment br. 18.) mogu dobiti visoka izluženja Zn i In.

Dobijeni rastvor pri uslovima luženja prikazanim u eksperimentu 18 prihvatljiv je za dalji tretman. S obzirom na cenu sumporne kiseline $u$ odnosu na druge koje su korišćene za luženje i uslove rada koji nisu rigorozni smatra se da je odabir ove kiseline isplativ. Dobijeni rastvor pri ovim uslovima može se dalje tretirati u cilju selektivnog izdvajanja metala iz rastvora.

\section{Karakterizacija čvrstog ostatka nakon luženja}

$S$ obzirom da je luženje u sumpornoj kiselini pokazalo najbolje rezultate, urađena je karakterizacija čvrstog ostatka nakon luženja.

Hemijska analiza čvrstog ostatka

Tabela 9 - Sadržaj metala u čvrstom ostatku nakon luženja u $\mathrm{H}_{2} \mathrm{SO}_{4}$

Table 9 - Metal content in solid residue after leaching in $\mathrm{H}_{2} \mathrm{SO}_{4}$

\begin{tabular}{|l|l|l|l|}
\hline Metal & $\mathrm{Cu}$ & $\mathrm{Zn}$ & $\mathrm{In}$ \\
\hline Koncentracija, \% & 0,24 & 0,05 & 0,0004 \\
\hline
\end{tabular}


Mineraloška analiza čvrstog ostatka nakon luženja

Difraktogram dobijen XRD analizom čvrstog ostka nakon kiselinskog luženja $\left(\mathrm{H}_{2} \mathrm{SO}_{4}\right)$ prikazan je na slici 3. U ovom uzorku identifikovani su minerali jarozit $\left(\mathrm{KFe}_{3}\left(\mathrm{SO}_{4}\right)_{2}(\mathrm{OH})_{6}\right)$, olovni barit $\left((\mathrm{Ba}, \mathrm{Pb}) \mathrm{SO}_{4}\right)$ i kvarc $\left(\mathrm{SiO}_{2}\right)$. Jarozit i olovni barit su najzastupljeniji minerali u uzorku, dok je kvarc manje zastupljen.

Napomena: olovni barit $\left((\mathrm{Ba}, \mathrm{Pb}) \mathrm{SO}_{4}\right)$ je barit $\mathrm{u}$ čijoj je kristalnoj rešetki deo atoma barijuma zamenjen atomima olova.

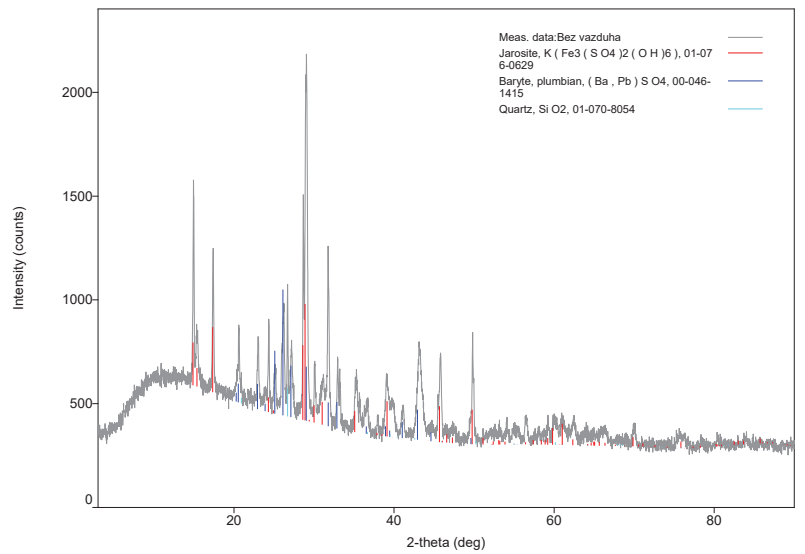

Slika 3 - XRD analiza čvrstog ostatka nakon kiselinskog luženja

Figure 3 - XRD analysis of solid residue after acid leaching

Na osnovu XRD i hemijske analize može se zaključiti da luženjem u $\mathrm{H}_{2} \mathrm{SO}_{4}$ kiselini nije došlo do destrukcije kristalne rešetke jarozita ali su izluženja korisnih metala (Cu, Zn i In) zadovoljavajuća.

\section{ZAKLJUČAK / CONCLUSION}

Za tretman otpadnog taloga jarozita korišćene su različite kiseline i $\mathrm{NaCl}$.

Može se zaključiti da se luženjem jarozita korišćenjem $\mathrm{HCl}$ kiseline pri najagresivnijim uslovima dobijaju visoka izluženja $\mathrm{Cu}, \mathrm{Zn}$ i In. Luženjem sa hlorovodoničnom kiselinom pri odabranim uslovima rad ne bi bio bezbedan zbog agresivne sredine.

Luženjem jarozita u azotnoj kiselini dobija se relativno dobro izluženje In ali i niska izluženja $\mathrm{Cu}$ i Zn. Luženjem sa azotnom kiselinom oslobađa se velika količina agresivnih azotovih oksida.

Luženje u rastvoru natrijum hlorida nije dalo zadovoljavajuća izluženja metala.
Luženjem u sumpornoj kiselini dobijaju se najbolja izluženja svih razmatranih metala.

$S$ obzirom na cenu sumporne kiseline u odnosu na druge koje su korišćene za luženje i uslove rada koji nisu rigorozni smatra se da je odabir ove kiseline opravdan. Dobijeni rastvor korišćenjem sumporne kiseline bi se dalje tretirao u cilju selektivnog izdvajanja metala.

\section{Zahvalnica / Acknowledgment}

Ovaj rad je finansijski podržalo Ministarstvo prosvete, nauke i tehnološkog razvoja Republike Srbije, ugovor br. 451-03-9 / 2021-14 / 200052.

\section{LITERATURA / REFERENCES}

[1] Yong-xing Zheng, Jin-fang LV, Wei Liu, Wen-qing Qin, Shu-ming Wen, (2016), An innovative technology for recovery of zinc, lead and silver from zinc leaching residue, Physicochem. Probl. Miner. Process. 52(2), 943-954.

[2] Yayun Wang, Huifen Yang, Weihao Zhang, Ronglong Song, Bo Jiang, (2018), Study on recovery of lead, zinc, iron from jarosite residues and simultaneous sulfur fixation by direct reduction, Physicochem. Probl. Miner. Process., 54(2), 517-526.

[3] Milićević, V., Arsić, Lj., Premović, J., Milićević, Z., Vidosavljević, S., Đokić, N. (2020), Nove tehnologije i inovacije: put do cirkularne ekonomije, Ecologica, 27(100), 675-682.

[4] Stanojević, D., Filipović-Petrović, L. (2014), Doprinos integrisanoj valorizaciji metala u hidrometalurgiji cinka, Zaštita materijala, 55(1), 11-25.

[5] Stanojević, D., Todorović, M., (1998), Valorisation of useful metals from by-products of hydrometallurgical manufacturing of zinc, 1st International Conference of Chemical Societies of the South-East European Countries: "Chemical Sciences and Industry", Solun, Greece, 1-4 June, 1998., Vol II, PO 729.

[6] Stanojevic, D., Rajkovic, M.B., Toskovic, D. (2006), Extraction of useful metals from leadsilver cake in the process of hydrometallurgical zinc production by leaching in calcium-chloride solution, Buletin of Electrochemistry, Karaikudi (India), 22, 337-341.

[7] Ilić, B., Sovtić, K., Mihajlović, D. (2019), Ekonomska i ekološka održivost Srbije - uslov podizanja kvaliteta života i zaštite životne sredine, Ecologica, 94 (2019), 193-198. 